\title{
Integration of Social Aspects in Decision Support, Based on Life Cycle Thinking
}

\author{
Annekatrin Lehmann ${ }^{1,2, *}$, Daniela Russi ${ }^{3}$, Alba Bala ${ }^{3}$, Matthias Finkbeiner ${ }^{1}$ \\ and Pere Fullana-i-Palmer ${ }^{3}$
}

1 Department of Environmental Technology, Technische Universität Berlin, Office Z1, Strasse des 17. Juni 135, D-10623 Berlin, Germany; E-Mail: matthias.finkbeiner@tu-berlin.de (M.F.)

2 Institute for Technology Assessment and Systems Analysis, Karlsruhe Institute for Technology, Hermann-von-Helmholtz-Platz, 76344 Eggenstein-Leopoldshafen, Germany

3 UNESCO Chair in Life Cycle and Climate Change, Escola Superior de Comerç Internacional (ESCI), Universitat Pompeu Fabra (UPF), Passeig Pujades, 1, E-08003 Barcelona, Spain; E-Mails: daniela.russi@esci.es (D.R.); alba.bala@esci.es (A.B.); pere.fullana@esci.es (P.F.)

* Author to whom correspondence should be addressed;

E-Mail: annekatrin.lehmann@campus.tu-berlin.de; Tel: +49-30-314-79501;

Fax: +49-30-314-21720.

Received: 17 January 2011; in revised form: 27 February 2011 / Accepted: 14 March 2011 / Published: 30 March 2011

Abstract: Recently increasing attention has been paid to complementing environmental Life Cycle Assessment (LCA) with social aspects. The paper discusses the selection of social impacts and indicators from existing frameworks like Social Life Cycle Assessment (SLCA) and Social Impact Assessment (SIA). Two ongoing case studies, addressing sustainability assessment within decision support, were considered: (1) Integrated Water Resources Management (IWRM) in Indonesia; and (2) Integrated Packaging Waste Management in Spain and Portugal (FENIX). The focus was put on social impacts occurring due to decisions within these systems, such as choice of technologies, practices or suppliers. Thus, decision makers-here understood as intended users of the studies' results - are not consumers that buy (or do not buy) a product, such as in recent SLCA case-studies, but mainly institutions that decide about the design of the water or packaging waste management system. Therefore, in the FENIX project, a list of social impacts identified from literature was sent to the intended users to be ranked according to their priorities. Finally, the paper discusses to what extent the entire life cycle is reflected in 
SLCA impact categories and indicators, and explains how both life-cycle and on-site-related social impacts were chosen to be assessed. However, not all indicators in the two projects will assess all stages of the life cycle, because of their varying relevance in the different stages, data availability and practical interest of decision makers.

Keywords: social impacts; social indicators; SLCA; SIA; LCA; sustainability assessment; integrated water resources management; packaging waste management; software; decision support

\section{Introduction—Social Sustainability}

The term sustainability and the question of how to achieve a sustainable development have been discussed in literature since the late 1970s. Even though various concepts, frameworks and definitions, exist (see e.g., [1,2]), sustainability generally refers to the preservation of a certain system or parts of this system for the well-being of future generations [3]. With regard to social sustainability, the intergenerational equity concept is complemented by the idea of intragenerational equity (e.g., [2,4]), addressing the well-being not only of future, but also of current, generations. Social sustainability assessment is often conducted by means of Social Impact Assessment (SIA) or by 'stretching' Environmental Impact Assessment (EIA) and Strategic Environmental Assessment (SEA) [5] to incorporate social issues. Increasing attention has recently been paid to the Social Life Cycle Assessment (SLCA) methodology, which intends to analyze the social impacts of a product, trying to avoid problem shifting among the different life cycle stages. SIA and SLCA are complementary tools, focusing on different scopes and objects of investigation. Both tools have been developed as 'social' complements to the environmental assessment tools, e.g., EIA and Life Cycle Assessment (LCA). The main difference between SIA and SLCA (such as between EIA and LCA) is the focus of the study. While SIA focuses on on-site specific impacts, SLCA considers the entire life cycle of products and mainly global impacts. Table 1 summarizes objectives and scopes of SLCA and SIA. The limitations of SLCA and SIA are described in detail in the Guidelines available for SIA [6] and SLCA [7] and are thus not explicitly addressed here.

Table 1. Overview-Social impact assessment (SIA) and Social Life Cycle Assessment (SLCA) according to SIA Guidelines [6] and SLCA Guidelines [7].

\begin{tabular}{|l|l|l|}
\hline & \multicolumn{1}{|c|}{ SIA } & \multicolumn{1}{|c|}{ SLCA } \\
\hline Objectives & $\begin{array}{l}\text { "...assess or estimate, in advance, the social } \\
\text { consequences that are likely to follow from specific } \\
\text { policy actions (including programs, the adoption of } \\
\text { new policies), and specific government actions." }\end{array}$ & $\begin{array}{l}\text { "...a social impact (and potential impact) assessment } \\
\text { technique that aims to assess the social and } \\
\text { socio-economic aspects of products ... along their } \\
\text { life cycle ..." }\end{array}$ \\
\hline Scope & $\begin{array}{l}\text { Impacts that occur at a single process and/or plant } \\
\text { Impacts that occur over the entire life cycle }\end{array}$ \\
\hline
\end{tabular}


Table 1. Cont.

\begin{tabular}{|l|l|l|}
\hline & \multicolumn{1}{|c|}{ SIA } & \multicolumn{1}{|c|}{ SLCA } \\
\hline $\begin{array}{l}\text { Assessment } \\
\text { procedure }\end{array}$ & $\begin{array}{l}\text { Different categories/social impact assessment } \\
\text { variables are provided, e.g., referring to population } \\
\text { characteristics, community and institutional } \\
\text { structures, political and social resources, individual } \\
\text { and family changes, community changes. } \\
\text { Relation of these variables to the project stages. } \\
\text { Stakeholder inclusion plays a major role. }\end{array}$ & $\begin{array}{l}\text { The Guidelines/methodological sheets suggest a set } \\
\text { of assessment indicators, classified according to } \\
\text { stakeholders or different impacts, but the final choice } \\
\text { depends on the characteristics of the analyzed } \\
\text { problem. There is still no agreement among scholars } \\
\text { on the aggregation and evaluation procedures. } \\
\text { Stakeholder inclusion plays a major role. }\end{array}$ \\
\hline
\end{tabular}

\subsection{Social Impacts and Assessment within Management Systems}

Social impacts are defined in the Guidelines for SLCA as '...consequences of positive or negative pressures on social endpoints...' (e.g., the stakeholder's well-being) or '... as consequences of social relations (interactions) coming along with an activity (production, consumption or disposal) or actions taken by stakeholders' [7]. The latter is similar to the definition provided in the SIA Guidelines describing social impacts as '...consequences to human populations of any public or private actions, that alter the ways in which people live, work, play, relate to one another, organize to meet their needs and generally cope as members of society' [6,8]. The Guidelines for Social LCA [7] were published by the Life Cycle Initiative (LCI) launched by the United Nations Environment Programme (UNEP) and the Society for Environmental Toxicology (SETAC) and present the state of the art of SLCA. Besides summarizing existing methodologies and approaches, so-called methodological sheets are provided by the Guidelines. Within these documents 'socially relevant characteristics or attributes to be assessed' - called 'subcategories' are described [9], indicators for the analysis are proposed and recommendations for data assessment are given. By now, the SLCA Guidelines have been applied only for a few case studies, e.g., for cut roses [10] and for note books [11]. The origin of social impacts and thus the link to potential improvement of the social performance can be classified as follows, reflecting the scopes of SIA and SLCA.

(1) Impacts due to the project and policy

(2) Impacts due to the technologies themselves (relevant in decision support, when alternative technological options are available and the 'more sustainable' should be chosen)

(3) Impacts due to behavior of companies within this system (relevant in decision support e.g., with regard to choosing a socially responsible company or revealing optimization potential in companies)

Social responsibility or sustainability performance of companies or organizations is often associated with Corporate Social Responsibility (CSR). While SIA and SLCA can be seen as tools to assess social aspects, CSR rather represents a framework. Activities with CSR approach are e.g., participating in or acting according to voluntary commitments like Global Compact [12], Dow Jones Sustainability Index [13] (as described by Jørgensen [14]) as well as the Declaration of Human Rights [15] or the International Labour Organization (ILO) standards [16]. Within SIA it is also referred to the international conventions on Human Rights and Worker Rights, which, according to UNEP [7], provide a good basis for a SLCA indicators framework. An overview of terms, methods and 
measurements within CSR is given e.g., in [17]. Since 2010, a 'Guidance on Social Responsibility' has also been available [18]. A study by Jørgensen [14] reveals that companies have an interest in extending or adapting the CSR scope by using SLCA (to include a life cycle and a productperspective), mainly for comparative assertions, use-stage assessments, and weighting of social impacts.

\subsection{Integrating Social Aspects in the Case Studies-Integrated Water Resources Management (IWRM) and Integrated Packaging Waste Management (FENIX)}

The paper examines the integration of a social assessment within decision support for two case studies: (1) IWRM-Integrated Water Resources Management: a five-year project (2008-2012) dealing with the implementation of appropriate technologies for water supply and waste water treatment in Indonesia. Within this project a study focuses on Life Cycle Sustainability Assessment (LCSA) of technologies, considering environmental, economic and social aspects; (2) FENIX — Giving Packaging a New Life!: a three-year European project (2010-2012), aiming at the development of a software that can include environmental, social and economic indicators, to assist municipalities, Green Dot Holders and regional governments in their choice between available options for packaging waste management. Table 2 summarizes the main features of these two projects.

Table 2. Life cycle based sustainability assessment in two case studies-Background and scope.

\begin{tabular}{|l|l|l|}
\hline & \multicolumn{1}{|c|}{ IWRM-project } & FENIX-project ('Giving Packaging a New Life') \\
\hline $\begin{array}{l}\text { Goal and scope } \\
\text { of the projects }\end{array}$ & $\begin{array}{l}\text { Life cycle based assessment of technologies within } \\
\text { an Integrated Water Resources Management } \\
\text { system, encompassing environmental, economic } \\
\text { and social aspects. } \\
\text { Contributing to sustainable development in the } \\
\text { Gunung Kidul, Java, Indonesia. }\end{array}$ & $\begin{array}{l}\text { Development of a Life Cycle based software for } \\
\text { decision support for packaging waste management, } \\
\text { encompassing environmental, economic and } \\
\text { social aspects. } \\
\text { Optimization of existing management systems in } \\
\text { Spain and Portugal }\end{array}$ \\
\hline $\begin{array}{l}\text { Objective: } \\
\text { social aspects }\end{array}$ & $\begin{array}{l}\text { Identification of social impacts and indicators } \\
\text { related to technologies and regarded as relevant } \\
\text { for classifying technologies as 'sustainable'. }\end{array}$ & $\begin{array}{l}\text { Identification of social impacts and indicators } \\
\text { related to waste management systems and regarded } \\
\text { as being relevant from a sustainability and } \\
\text { decision-maker perspective. }\end{array}$ \\
\hline Intended & $\begin{array}{l}\text { Choosing sustainable and appropriate technologies } \\
\text { in the planning phase, mainly with regard to } \\
\text { technology transfer in similar regions. } \\
\text { Practical application and methodological } \\
\text { enhancement of SLCA. }\end{array}$ & $\begin{array}{l}\text { Broadening the scope of a decision support tool } \\
\text { to assist local and regional waste managers } \\
\text { from Spain and Portugal in finding more } \\
\text { eco-efficient and sustainable solutions for } \\
\text { packaging waste management. } \\
\text { Practical application and enhancement of SLCA. }\end{array}$ \\
\hline
\end{tabular}

Integrated Water Resources Management (IWRM) aims at '...maximizing the economic and social welfare (...) without compromising the sustainability of vital ecosystems' [19]. Here the term generally refers to (1) protection and maintenance of the resource water, (2) appropriateness of technologies (e.g., simplicity and acceptance by the local population); and (3) durability (of technologies). Sustainability assessment within the IWRM in Indonesia is conducted using two 
approaches; the Integrative Sustainability Concept of the Helmholtz Association (HGF concept) [2] and - with focus on products and life cycle - the Life Cycle Sustainability approach, combining LCA, Life Cycle Costing (LCC) and SLCA [1,20,21]. Core element of the HGF concept is a set of sustainability rules, describing the minimum requirements of a sustainable development (e.g., provision of basic services). The rules (e.g., derived from Millennium Development Goals) serve as orientation with regard to future development goals as well as criteria for evaluation of the current status. They are substantiated by indicators, allowing an adaption to different contexts (e.g., to the water sector). The HGF-concept is used within the IWRM for example for assessing the on-site social impacts of an improved water supply and waste water disposal. Within the IWRM project, life cycle based assessment methods, like LCA and LCC are used for analyzing alternative technologies and identifying 'more sustainable' technologies [22]. The present study examines SLCA as a complementary method to LCA, LCC and HGF for integrating social aspects for technology assessment with a life cycle based and product/process related perspective.

The FENIX project aims at developing a user friendly life cycle thinking based decision support tool (software) for packaging waste management in Spain and Portugal, focusing on environmental impacts but also taking into account economic and social aspects. The tool is intended to be used by municipalities and other territorial organizations in Spain and Portugal to perform more eco-efficient and sustainable management of packaging waste, but will be adaptable also to other European realities. Since so far no international consensus exists on how to select and apply social indicators, the integration of social aspects in the software is considered as one of the biggest challenges within the FENIX-project.

The UNEP-SETAC SLCA framework and its methodological sheets are used as a starting point for selecting social subcategories and indicators for both case studies. Additional social aspects identified as being of relevance for decision support when taking into account site-specific characteristics of the case studies (e.g., institutional structure or local culture) were included as well. Thus, the intention of this paper is not to come out with a list of templates of indicators for social sustainability assessment in water or waste management systems, but merely to show two practical applications of SLCA and to discuss some methodological challenges that were encountered. Even though data availability is often a problem when performing a SLCA, in both IWRM and FENIX sufficient data availability was assumed when choosing the social subcategories. In fact, the IWRM-study primarily focused on identifying those subcategories (and indicators) that are appropriate to describe the operation-phase of technologies within SLCA - following a more a methodological approach than actually looking for data. Regarding FENIX, the software is developed in close co-operation with future users, who may be able to provide the necessary data or to promote the assessment of — so far unavailable — data.

When assessing social impacts within the two case studies it can be differentiated between (1) social impacts related to the function provided by the system (den Boer [23] refers to that as 'social function', one of three social sustainability perspectives besides social acceptability and social equity) - in case of IWRM, e.g., improved living conditions due to increased water supply and safe waste water disposal - and (2) those related to the alternatives examined (as the objectives of decision processes). Taking the latter perspective, it is assumed here that the function of the systems (improved water provision or recycling of packaging waste) is not under consideration. Resulting social impacts 
e.g., the extent to which values and goals related to social welfare are met, are measured [21], e.g., with the Human Development Index (HDI) [24] or the Gini-coefficient [25].

The scope of this paper is rather to address social impacts that occur due to decisions concerning alternative technologies, management practices or companies. In the IWRM case study, water is considered as a product (as in [26]), whose life cycle needs to be assessed, from water extraction to waste water disposal (see Figure 1). Those social impacts are assumed to be of main relevance for decision makers that might change with alternative technologies to provide, distribute or treat water and waste water and companies/institutions providing these services. The same applies for decision support regarding alternative technologies/companies for collecting, transporting, storing or treating packaging waste.

\section{Methodology}

\subsection{Literature Review and Selection of a Preliminary List of Social Subcategories and Indicators}

Social subcategories and indicators intended to contribute to sustainability assessment in decision support for the two case studies, have been chosen based on a combined top-down and bottom up-approach (as in $[27,28]$. Top-down refers to widely generally recognized societal values. In the SLCA Guidelines, numerous social issues of interest are addressed (as 'subcategories'), classified according to five main categories of stakeholders (workers/employees, local community, society (national and global), consumers and value chain actors) [7,9] and are described by various social indicators. Indicators can be quantitative, qualitative and semi-quantitative. Indicators (e.g., excessive hours of work) are used to describe ('measure') subcategories (e.g., working conditions). Subcategories can be further aggregated to impact categories (e.g., working conditions) [7]. The indicators were used as a starting point to identify suitable subcategories and indicators for the case studies. Further literature review, a user requirement analysis (URA) in the FENIX-project and socioeconomic studies on living conditions prior to and within the IWRM-project [29], have been conducted in order to consider social issues of interest in the regional and case-specific context (bottom-up approach). The URA in the FENIX-project The URA in the FENIX-project was performed in waste Management Units (MU) of Spain and Portugal. It was a survey to assess their current knowledge about LCA approaches and also to identify their needs and requirements for the software tool that will be developed in FENIX. The final questionnaire was sent to 440 MUs in Spain. 220 of them answered the questionnaire, achieving a representative sample with a confidence level of $95 \%$ and a margin of error of $6 \%$. The questionnaire was also sent to all MUs in Portugal (34). 25 of them answered the questionnaire $(73.5 \%)$.

LCA software developed or adapted for water or waste management systems have also been reviewed in practice. Out of five LCA software programs examined for waste management (IWM-2 (Procter and Gamble, 1999), IWM Canada (Procter and Redfirn, 1999), Wrate (Golder Associates for UK Environment 2002-2009), Easewaste (DTU, Denmark, 2006), LCA-IWM:MSWMS (TU Darmstadt, 2005)), social aspects have been considered only within the IWM-LCA software [23]. With regard to water management, specific software exists as well (e.g., [30,31]), but do not include social aspects. 
With regard to the FENIX and IWRM projects, 13, respectively 14 subcategories, were selected by literature review and discussion with experts (Tables 3 and 4).

\subsection{Validation of Social Aspects by Stakeholder Inclusion}

A stakeholder analysis should play a major role in the selection of social indicators [7,32], Stakeholders can be included in selecting indicators either in a participatory process or in a review process [6].

Against this background, the preliminary list of 13 social subcategories was sent to a sample of the three identified and intended types of users of the FENIX-software: 17 Spanish Autonomous Communities (out of which 10 answered); 20 Management Units - a Management Unit (MU) is either a single municipality or a group of municipalities who jointly manage their waste) - in Spain and 10 in Portugal (out of which 20 respectively 9 answered) and the Spanish and Portuguese Green Dot Holder entities. As it was not possible to send the list to a large sample, 20 municipalities in Spain and 10 in Portugal have been representatively selected taking into account criteria as type of MU, number of different waste collection systems implemented in each MU and population density. They were asked to value the importance of the 13 preselected social subcategories shown in Table 3 giving them a score. The MUs, the Green Dot Holders and the representatives of the Spanish Autonomous Communities were asked to distribute 140 points among the 13 subcategories included in the preliminary list. The reason for the number of points is that the first preliminary list included 14 social subcategories and it was decided to give a score of 10 per subcategory. Even though one subcategory was removed from the list during the discussion phase, the points to be assigned remained 140 and were not changed to 130. In any case, the results are presented in Table 4 in percentage terms instead of numbers. The answers were then the basis for the final selection of subcategories to be used within the FENIX software.

With regard to the IWRM, SLCA is intended to be used to support decisions between alternative technologies in developing regions. Decision makers in that sense can be municipalities, but also parties financing developing projects and promoting technology transfer/multiplication. An URA analysis as in the FENIX-study (stakeholder analysis with focus on decision makers) has not been conducted. However, the social framework has been considered and literature review and socio-economic studies (mainly based on questionnaires and interviews with the local population) $[29,33,34]$ have been used to identify relevant social aspects related to technologies.

\section{Results and Discussion}

Main objective of the case studies presented here is the integration of social aspects in decision support processes and decision support tools. As a complement to LCA used in the studies, the methods of SLCA have been consulted. However, the final selection of social subcategories and indicators is not restricted to this life cycle perspective. A focus was laid as well on the demand and requirements formulated by those who will in the end use the results of the study as a basis for their decisions. 


\subsection{Social Aspects Considered in the Case Studies}

Table 3 summarizes the social aspects considered in the two case studies, divided into two categories: (1) social aspects (subcategories) addressed in the SLCA-Guidelines; and (2) social aspects obtained from other literature sources on social impact assessment (including existing software tools) or the URA in the case of FENIX. Indicators to assess the subcategories are provided within the SLCA-Guidelines [9]. However, while conducting a SLCA, it will be necessary to '...find and (re-)define the appropriate indicators (to assess the subcategories) adapted to the particular context and understanding' [7]. Consequently, for the two case studies, which address different topics and also differ in their regional context and stage of development, two different lists of social indicators/impacts were derived. The terms indicators and impacts are not strictly separated though generally, indicators 'measure' effects that are grouped to certain impacts. As depending on the perspective some indicators can be understood also as impacts, Table 3 prefers the term social aspect.

Table 3. Social subcategories and indicators considered within decision support in an Integrated Water Resources Management (IWRM) and for Integrated Packaging Waste Management (FENIX), gained from SLCA-Guidelines and further literature.

\begin{tabular}{|l|l|l|}
\hline & IWRM & FENIX \\
\hline SLCA-Guidelines- & Health and safety & Health and safety ${ }^{2}$ \\
& $\begin{array}{l}\text { Hours of work } \\
\text { Local employment } \\
\text { Community engagement and cultural heritage } \\
\text { Corruption } \\
\text { Technology development } \\
\text { Public commitment to sustainability issues } \\
\text { Feedback mechanisms } 1\end{array}$ & $\begin{array}{l}\text { Equal opportunities } \\
\text { Local employment } \\
\text { (unemployment) }\end{array}$ \\
\hline $\begin{array}{l}\text { Social aspects from } \\
\text { assessment literature }\end{array}$ & $\begin{array}{l}\text { Existence of institution responsible for water management } \\
\text { Existence of continuously annual investment for water sector } \\
\text { Response time to repair a broken pipe } \\
\text { Number of institutions which are responsible for a technology } \\
\text { and respectively involved in actions related to its 'functioning' } \\
\text { Percentage of successfully implemented technologies } \\
\text { (e.g., within a development aid project) in the sector } \\
\text { respectively projects in the region/country/sector } \\
\text { Reported trust into social institutions }\end{array}$ & $\begin{array}{l}\text { Odor } \\
\text { Comfort } \\
\text { Comprehension }\end{array}$ \\
\hline
\end{tabular}

${ }^{1}$ The subcategory can be used for reflecting the acceptability of technologies from a user (consumer) perspective.

2 This subcategory e.g., addresses further social aspects proposed on the FENIX-pre-list, such as stressful (psychological) working conditions and labor rights violations. ${ }^{3}$ Sources: [29,33-35] and own considerations.

Social impacts (and indicators) as health and safety, local employment or hours of works, affecting mainly the stakeholder categories worker and local community were included in both lists. Those aspects can be allocated to the stages along the life cycles of the product water (e.g., water distribution or water treatment) respectively packaging waste (e.g., waste collection or waste treatment). The aspects can be observed on-site and be assessed as impacts which occur during the operation phase of 
technologies. Important social topics like child labor, enforced labor or fair payment have not been included here as they are not considered as relevant in industrialized countries, such as Spain and Portugal. The same applies for the investigation area considered in the IWRM-study.

However, following a life cycle approach, impacts which cannot be observed 'on-site', such as working conditions in upstream processes when producing chemicals for water or waste treatment processes, should be considered as well in decision processes e.g., on alternative technologies as well. Nearly $70 \%$ of worldwide child labor occurs in the agricultural sector, about $20 \%$ in the service sector and about $10 \%$ in the industry (like mining) [36]. Those sectors were assumed to be of minor relevance for the assessed case studies. Of course this can be discussed controversially, but for these studies child labor has not been included in the final list of social impacts.

Impacts on the stakeholder groups society, consumers and value chain actors are mainly related to companies' behavior and reflect how organizations understand and how they promote social responsibility among its suppliers. In the FENIX study, those aspects were considered to be (so far) of minor importance for decision makers and have not been included. Instead, additional social aspects related to processes in waste management (e.g., odor or noise) were added to the preliminary list, which was sent to the FENIX users.

Odor and noise can also be regarded as environmental issues and are included in some LCA impact assessment methods. They can be considered as important site-specific social impacts as well, due to the relation to the well-being of e.g., the neighborhood/community or workers. Moreover, they influence the acceptance, which is crucial in the decision process.

It is also noteworthy to observe that the potential software users did not add any further aspect to the preselected list of subcategories, implying that relevant social aspects were already addressed on the list.

In the methodological approach of the IWRM case study, the stakeholder groups society and consumers are addressed as well. Social subcategories that can be associated to both groups like public commitment to sustainability issues or feedback mechanism address social responsibility of organizations or institutions and can reflect to what extent the needs of the users are met. This aspect is crucial with regard to the social conditions in the area under investigation of the IWRM project and questions related to successful technology implementation. The implementation depends e.g., on acceptance of technologies and is also addressed by additional social indicators, like 'reported trust', identified from further literature and based on findings from socioeconomic studies within the IWRM-project. With regard to water management (in developing regions or countries), acceptance or trust can be expressed for example by the willingness of the population to pay for piped water, despite unsecure water supply and no guarantee from the responsible bodies/institutions.

Table 4 shows the scores assigned to the 13 pre-selected subcategories by the FENIX final users.

In general, the survey shows that for management units or municipalities, site-specific impacts like 'odor' and 'noise' are considered of high importance, whereas factors such as physical and psychological working conditions or local employment were considered to be of lower importance. However, for regional governments the most important perceived problem is the comfort of the system. Green Dot Holders seem to be more worried about social problems related to their direct activities such as urban space occupied by containers, health conditions of workers and visual impact. This is probably due to the fact that those impacts within the management system (especially when 
caused by companies' behavior) can be assumed to be similar within one region and for the regarded alternatives. However, this of course depends on how the system boundaries are set, as it is discussed in Section 3.2. Based on the results of this combined top-down and bottom-up approach, a final list of subcategories was defined for implementation in the software: (1) odor; (2) workplace health and safety; (3) visual impact; (4) noise; (5) comfort; (6) urban space; (7) comprehension; (8) unemployment.

Table 4. Score assigned to the 13 selected social aspects (subcategories) by FENIX final users.

\begin{tabular}{|c|c|c|c|c|c|}
\hline \multirow[b]{2}{*}{ No. } & \multirow[b]{2}{*}{ Social aspects } & \multirow{2}{*}{$\begin{array}{c}\begin{array}{c}\text { Regional } \\
\text { Government }\end{array} \\
(\mathbf{N}=\mathbf{1 0}) \\
\end{array}$} & \multicolumn{2}{|c|}{ Management Units/Municipalities } & \multirow{2}{*}{$\begin{array}{c}\text { Green Dot Holders } \\
\qquad(\mathrm{N}=2) \\
\end{array}$} \\
\hline & & & $\operatorname{ESP}(\mathbf{N}=\mathbf{2 0})$ & PORT $(\mathrm{N}=9)$ & \\
\hline 1 & Odor & $9.4 \%$ & $12.6 \%$ & $13.7 \%$ & $7,9 \%$ \\
\hline 2 & Workplace health and safety & $8.5 \%$ & $6.4 \%$ & $9.2 \%$ & $12,1 \%$ \\
\hline 3 & Visual impact & $8.9 \%$ & $9.9 \%$ & $8.6 \%$ & $10,0 \%$ \\
\hline 4 & Noise & $9.5 \%$ & $11.0 \%$ & $12.1 \%$ & $6,1 \%$ \\
\hline 5 & Comfort $^{1}$ & $11.3 \%$ & $10.4 \%$ & $8.7 \%$ & $6,1 \%$ \\
\hline 6 & Urban space $^{2}$ & $8.4 \%$ & $8.4 \%$ & $6.6 \%$ & $8,6 \%$ \\
\hline 7 & Comprehension $^{3}$ & $8.9 \%$ & $10.0 \%$ & $7.0 \%$ & $6,4 \%$ \\
\hline 8 & Labor right violations & $5.7 \%$ & $5.5 \%$ & $5.4 \%$ & $8,2 \%$ \\
\hline 9 & Private space & $8.4 \%$ & $5.7 \%$ & $7.1 \%$ & $10,0 \%$ \\
\hline 10 & Excessive work & $6.1 \%$ & $5.8 \%$ & $5.5 \%$ & $6,8 \%$ \\
\hline 11 & Unemployment & $5.4 \%$ & $4.9 \%$ & $4.8 \%$ & $7,9 \%$ \\
\hline 12 & Unequal opportunities & $4.9 \%$ & $4.8 \%$ & $5.1 \%$ & $5,4 \%$ \\
\hline \multirow[t]{2}{*}{13} & Stressful working conditions & $4.5 \%$ & $4.8 \%$ & $6.4 \%$ & $4,6 \%$ \\
\hline & Total & $100 \%$ & $100 \%$ & $100 \%$ & $100 \%$ \\
\hline
\end{tabular}

${ }^{1}$ Comfort: refers to the time that a citizen needs for waste management (e.g., distance to/number of bins and containers). ${ }^{2}$ Urban space: refers to space occupied by the waste storage system or a treatment plant, in a particular city, in relation to the actual availability of the real space in this city. ${ }^{3}$ Comprehension: values the understanding as a measure of acceptance of the system at the stage of temporary storage.

Thus, the final selection included only those subcategories that received a score above $10 \%$ by at least one category of users. However, the impact category 'labor rights violations' was not included in the final selection because it does not depend on waste management options. Finally, the category 'unemployment' was included in the final list as it was considered important from the point of view of society as a whole, even though none of the users assigned a high score to this category.

Next, the following tasks will be carried out in the project: choice of indicators for evaluating the selected subcategories for three stages of waste management (collection, transport, processing/ recycling); collection of data; software validation with end users and result interpretation. 


\subsection{System Boundaries in SLCA from a Practical Point of View-How Much Life Cycle Is Included in} the Assessment

The SLCA approach adopted in the two case studies implies that social impacts are analyzed for all life cycle stages within the management systems for the products water (from water supply to waste water treatment) and waste (from waste collection to waste treatment) (Figure 1). Based on the example of the social aspect 'odor' in the FENIX-study; from a social sustainability perspective, increasing the quality of life of e.g., the local population would mean to choose this technology that causes the least odor. Then, the decision actually refers to a site specific impact, which occurs at only one life cycle stage (e.g., waste collection).

With regard to a life cycle based social assessment of alternatives, also upstream and downstream processes are included, indicated with the horizontal grey line in Figure 1. However, social aspects as noise or odor, identified as relevant for decisions in the FENIX-study, here refer to the on-site impacts caused by e.g., the operation of technologies (operation-phase)/practices for waste collection. Social impacts, which depend more on the company's behavior (e.g., stressful working conditions) — here considered of minor importance for decision makers - can be of greater relevance when system boundaries are extended and e.g., the production of imported process materials like chemicals for waste treatment is included.

Figure 1. Simplified Life Cycle chains in water and waste management systems (functional units: provision of a certain amount of water (and disposal of respective waste water), treatment/disposal of a certain amount of packaging waste).
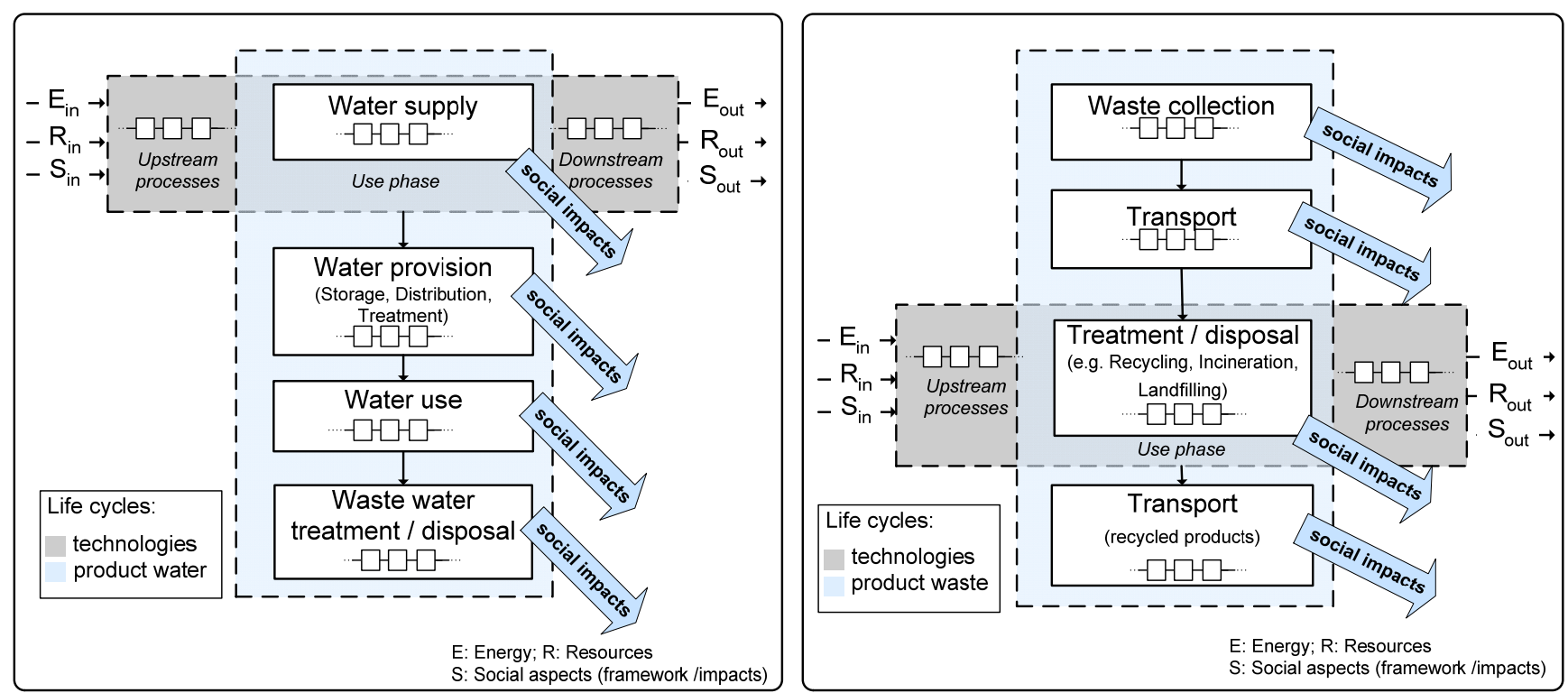

With regard to technology assessment in IWRM, social aspects crucial for decision support and related to only one life cycle phase - the 'operation phase' of technologies - are also of interest in the IWRM-study, referring here to implementation conditions and acceptance. With regard to a life cycle based technology assessment within IWRM, social subcategories derived from the SLCA-Guidelines, such as workplace health and safety, hours of work or employment are intended to be assessed for upstream processes as well. This includes e.g., the provision and disposal of process materials 
(e.g., chemicals for water treatment) for technology operation and maintenance, as well as the construction phase of technologies. Since some of the technological alternatives for water supply, treatment or waste water disposal to be analyzed are developed and implemented within the IWRM-project, data are principally available. In cases where social impacts can be directly allocated to a technology e.g., hours of work for construction or operation, the information gained by SLCA can be useful to compare technologies against the background of technology transfer or multiplication to similar regions. However, social aspects, which are mainly caused by company (or suppliers) behavior, such as stressful working conditions or fair wages, have to be assessed independently for the respective cases.

From the perspective of decision-makers in management systems it is important to determine how a company's social responsibility can be included in decision making processes. Assessing social aspects related to companies in order to 'chose' the one with the best social performance (or in order to reveal improvement potential) might be feasible with regard to companies 'on-site'. But it is questionable to what extent decision makers in practice (e.g., municipalities in the waste management case study) are able or interested in tracing back social impacts in other life cycle stages. Even though indicators are proposed in the SLCA Guidelines to assess whether a company or organization promotes social responsibility among its suppliers [9], decision makers eventually have to 'trust' the companies and make their choice according, for example, to the company's participation in CSR activities. With an expected increasing awareness level concerning SLCA, decision makers could ask companies to extend their scope of CSR by considering a life cycle thinking approach. Although assessing the full life cycle of a product is seen as being 'rarely possible' from a company's perspective [14], at least exerting influence on the social performance on their first tier suppliers can be expected, which in turn should impact that they do the same with theirs.

However, since currently no standardized lists for social issues are available_-even though efforts exist (e.g., by Global Reporting Initiative GRI [37]) — differences might occur between individual companies [7]. Criticisms on CSR from NGOs or trade unions [38] — and actually so far also true for SLCA—refer to this lack of standardization and reporting.

\section{Recommendation and Outlook}

Based on two case studies, this paper discusses the integration of social aspects within decision processes. Available (social) sustainability assessment tools address a big variety of social issues, using numerous social indicators. In the FENIX study, only those social issues are considered which are affected by a decision made within the packaging waste management system at the stages of collection, transport or treatment of the packaging waste. Aspects like noise or odor obviously impact humans' well-being and consequently decrease the acceptance of local community. Social acceptance however is needed not only with regard to the well-being of directly affected stakeholders but also with regard to fulfilling the 'function' of the management system (water provision and recycling of waste). The functions of the systems themselves - though not the topic of this paper-may also contribute to sustainable development. In the FENIX-project for example, a correct waste collection (which depends also on acceptance of the collection system) is the first step on the way for 'giving packaging a new life'. With regard to the IWRM-project, acceptance and appropriateness considerably 
influence the direct responsibility for technologies. This is considered as one condition for effectiveness and sustainability of projects [39].

Both case studies include: (1) social aspects used to describe only on-site social impacts occurring in the water respectively packaging waste management without showing a life cycle relation (thus can be seen more as indicators of SIA); and (2) social aspects which are considered along the life cycle of the management alternatives (e.g., alternative technologies, companies). The latter have been considered to a lesser extent in the FENIX study. Reasons for not considering the life cycle perspective in all indicators are differing relevance in the stages, data availability and practical interest of decision makers.

Not addressed in this paper but a topic of further research, is the question of evaluating the social indicators. No standardized method exists so far, although the UNEP Guidelines provide two proposals. Case studies conducted following the Guidelines, e.g., by [11], evaluate indicators proposed (e.g., child labor) with regard to their influence on selected impact categories (e.g., human rights). In this regard, performances/effects of alternatives are assessed (ranking from very good to very poor performance and very positive to very negative effects). As a result, processes within the product system can be labeled as having a (very) positive, indifferent or (very) negative effect on the impact category.

As in LCA, the question of how to deal with opposing results for different social issues (e.g., one technology/process produces more noise but less odor than the alternative) remains. One solution may be to establish a weighting system, based on the stakeholders' priorities identified during the indicator/impact selection process. With regard to this, transparency and reporting-as in LCA - is crucial.

Since social impacts play a major role in sustainability assessment, every effort to integrate social aspects in decision processes and to combine them with existing methods (such as LCA or LCC) is highly recommended even if - due to methodological and practical restrictions — only some aspects of (social) sustainability are addressed.

\section{Acknowledgements}

This paper was written during a research stay of the corresponding author at the Environmental Management Research Group (GiGa) at ESCI, Universitat Pompeu Fabra (ESCI-UPF), financially supported - as a research travel scholarship - by Karlsruhe House of Young Scientists (KHYS). The corresponding author gratefully acknowledges this support by KHYS and would also like to thank the research groups GiGA, ITAS and SEE for their support and contribution. Part of the research of this paper was financed by the project "Fenix-Giving packaging a new life" (LIFE08 ENV/E/000135). The authors would like to thank the Life+Programme and the Spanish and Portuguese Green Dot Holders.

\section{References}

1. Klöpffer, W.; Grahl, B. Ökobilanz (LCA)_Ein Leitfaden für Ausbildung und Beruf; Wiley-VCH: Weinheim, Germany, 2009. 
2. Kopfmüller, J.; Brandl, V.; Jorissen, J.; Paetau, M.; Banse, G.; Coenen, R.; Grunwald, A. Nachhaltige Entwicklung integrativ betrachtet-Konstitutive Elemente, Regeln, Indikatoren. Global zukunftsfähige Entwicklung-Perspektiven für Deutschland 1; edition sigma: Berlin, Germany, 2001.

3. Klauer, B. Was ist Nachhaltigkeit und wie kann man eine nachhaltige Entwicklung erreichen? Zeitschrift für angewandte Umweltforschung 1999, Jg., 12.

4. Bauer, S. Leitbild der Nachhaltigen Entwicklung. In Informationen zur politischen Bildung; Bundeszentrale für politische Bildung: Bonn, Germany, 2008.

5. Colantonio, A. Traditional and Emerging Prospects in Social Sustainability. In Measuring Social Sustainability: Best Practice from Urban Renewal in the EU 2008/02: EIBURS Working Paper Series; European Investment Bank: Luxembourg, 2008.

6. Interorganizational Committee on Guidelines and Principles for Social Impact Assessment. Guidelines and Principles for Social Impact Assessment; NOAA Technical Memorandum NMFS-F/SPO; International Association for Impact Assessment (IAIA): Belhaven, NC, USA, 1994.

7. UNEP. Guidelines for Social Life Cycle Assessment of Products; UNEP-SETAC Life-Cycle Initiative: Paris, France, 2009.

8. Burdge, R.J. A Conceptual Approach to Social Impact Assessment: Revised Edition Collection of Writings by Rabel J. Burdge and Colleagues; Social Ecology Press: Middleton, WI, USA, 1998.

9. Methodological Sheets of Sub-Categories of Impact for a Social LCA. Available online: http://www.estis.net/sites/lcinit/default.asp?site=lcinit\&page_id=EDA1E98F-412F-4F51-B4073A7E006E1B83 (accessed on 10 September 2010).

10. Franze, J.; Ciroth, A. Social Life Cycle Assessment of Roses-a Comparison of Cut Roses from Ecuador and the Netherlands. In Proceedings of the Life Cycle Assessment Conference Boston IX, Boston, MA, USA, 29 September-2 October 2009.

11. Franze, J.; Ciroth, A. Social LCA of an Ecolabeled Notebook. In Proceedings of the Life Cycle Assessment Conference Portland X, Portland, OR, USA, 2-4 November 2010.

12. United Nations Global Compact; United Nations: New York, NY, USA, 2007.

13. Dow Jones Sustainability Index; SAM Indexes: Zurich, Switzerland, 2007.

14. Jørgensen, A.; Hauschild, M.Z.; Jørgensen, M.S.; Wangel, A. Relevance and feasibility of social life cycle assessment from a company perspective. Int. J. Life Cycle Assess. 2009, 14, 204-214.

15. United Nations. The Universal Declaration of Human Rights. Available online: http://www.un.org/en/documents/udhr/index.shtml (accessed on 22 December 2010).

16. Applying and Promoting International Labour Standards; International Labour Organization: Geneve, Switzerland, 2001.

17. Corporate Social Responsibility: Trend oder Modeerscheinung? Mueller, M.H., Schaltegger, S.H., Eds.; Oekom Verlag: Munich, Germany, 2007.

18. ISO26000:2010, Guidance on Social Responsibility; International Organization for Standardization (ISO): Geneve, Switzerland, 2010.

19. Global Water Partnerships-Technical Advisory Committee (GWP-TAC). Integrated Water Resources Management; Global Water Partnerships: Stockholm, Sweden, 2000. 
20. Kloepffer, W. Life Cycle Sustainability Assessment of Products (with Comments by Helias A. Udo de Haes). Int. J. Life Cycle Assess. 2008, 13, 89-95.

21. Finkbeiner, M.; Schau, E.M.; Lehmann, A.; Traverso, M. Towards life cycle sustainability assessment. Sustainability 2010, 2, 3309-3322.

22. BMBF-Verbundprojekt Integriertes Wasserressourcen-Management (IWRM) in Gunung Kidul, Java, Indoneisen. Available online: http://www.iwrm-indonesien.de/ (accessed on 10 September 2010).

23. den Boer, E.; den Boer, J.; Berger, J.; Jager, J.; Rodrigo, J.; Meneses, M.; Castells, F.; Yildiz, U.N.; Dilewski, G.; Boran, O. The Use of Life Cycle Assessment Tool for the Development of Integrated Waste Management Strategies for Cities and Regions with Rapid Growing Economies LCA-IWM. Deliverable Report: Social Sustainability Criteria and Indicators for Waste Management (Work Package 5); Institut WAR, Technische Universitaet Darmstadt (TUD): Darmstadt, Germany, 2005.

24. UNDP. Human Development Report 2010. Available online: http://hdr.undp.org/en (accessed on 24 March 2011).

25. Gini, C. Measurement of Inequality of Incomes. Econ. J. 1921, 31, 124-126.

26. Lassaux, S.; Renzoni, R.; Germain, A. Life cycle assessment of water from the pumping station to the wastewater treatment plant. Int. J. Life Cycle Assess. 2007, 12, 118-126.

27. Dreyer, L.C.; Hauschild, M.Z.; Schierbeck, J. A Framework for social life cycle impact assessment. Int. J. Life Cycle Assess. 2006, 11, 88-97.

28. Kruse, S.A.; Flysjö, A.; Kasperczyk, N.; Scholz, A.J. Socioeconomic indicators as a complement to life cycle assessment — an application to salmon production systems. Int. J. Life Cycle Assess. 2009, 14, 8-18.

29. Scholz, U.; Unger, B.; Lux, T. Sozioökonomische Analyse der potenziellen WassernutzerTeilprojekt 6 im Verbundprojekt „Erschließung und Bewirtschaftung unterirdischer Karstfließgewässer in Mitteljava, Indonesien. Abschlussberich; Institut für Geografie (IfG): Gießen, Germany, 2004. Available online: http://www.hoehlenbewirtschaftung.de/Deutsch/Files/ TP6_Abschlussbericht.pdf (accessed on 10 September 2010).

30. TOWEFO Project-Towards Effluent Zero Homepage. http://spring.bologna.enea.it/towefo/ ip_default.asp (accessed on 16 September 2010).

31. WEST Water-Energy Sustainability Tool. Available online: http://www.ce.berkeley.edu/ horvath/ west.html (accessed on 16 September 2010).

32. Jørgensen, A.; LeBocq, A.; Nazarkina, L.; Hauschild, M. Methodologies for social life cycle assessment. Int. J. Life Cycle Assess. 2008, 13, 96-103.

33. Nayono, S. Governing Water-Selecting Indicators for Sustainability Assessment of Integrated Water Resources Management in Gunung Kidul, Java, Indonesia, 2009, unpublished work.

34. Saleth, R.M.; Dinar, A. Evaluating Water Institutions and Water Sector Performance; World Bank: Washington, DC, USA, 1999.

35. Renn, O.; Deuschle, J.; Jäger, A.; Weimer-Jehle, W. Leitbild Nachhaltigkeit_Eine normative-funktionale Konzeption und ihre Umsetzung; VS Verlag: Wiesbaden, Germany, 2007. 
36. Hagemann, F.; Diallo, Y.; Etienne, A.; Mehran, F. Global Child Labour Trends 2000 to 2005; International Programme on the Elimination of Child Labour (IPEC), Statistical Information and Monitoring Programme on Child Labour (SIMPOC): Geneva, Switzerland, 2006.

37. Global Reporting Initiative: Sustainability Reporting Guidelines; Global Reporting Initiative: Boston, MA, USA, 2002.

38. Nelson, J. The Public Role of Private Enterprise: Opportunities, and New Models of Engagement. Corporate Social Responsibility; Initiative Working Paper No. 1; John F. Kennedy School of Government, Harvard University: Cambridge, MA, USA, 2004. Available online: http://www.hks.harvard.edu/m-rcbg/CSRI/publications/workingpaper_1_nelson.pdf (accessed on 24 March 2011).

39. Capacity Development für nachhaltige Entwicklung. Eine Kernaufgabe der GTZ; GTZ Policy Paper No. 1; Deutsche Gesellschaft für Technische Zusammenarbeit (GTZ) GmbH: Eschborn, Germany, 2003.

(C) 2011 by the authors; licensee MDPI, Basel, Switzerland. This article is an open access article distributed under the terms and conditions of the Creative Commons Attribution license (http://creativecommons.org/licenses/by/3.0/). 